\title{
Synchronization of Kainate-Induced Epileptic Activity via GABAergic Inhibition in the Superfused Rat Hippocampus
} In Vivo

\author{
Roustem Khazipov and Gregory L. Holmes \\ Section of Neurology, Neuroscience Center at Dartmouth, Dartmouth Medical School, Lebanon, New Hampshire 03756
}

\begin{abstract}
We studied cellular mechanisms of synchronization of epileptiform activity induced by kainic acid in a novel preparation of superfused rat hippocampus in vivo. Under urethane anesthesia, kainate induced epileptic population spikes occurring at $30-40 \mathrm{~Hz}$. Pyramidal cells fired exclusively during population spikes with an average probability of 0.34 on rebound of rhythmic $\mathrm{GABA}_{\mathrm{A}}$-mediated inhibitory postsynaptic events. Excitatory synaptic events contributed little to seizure activity. Rhythmic epileptiform activity was suppressed by blocking $\mathrm{GABA}_{\mathrm{A}}$ receptors and was slowed by barbiturates. Thus, GABAergic inhibition is instrumental in synchronizing kainateinduced epileptiform rhythmic activity in the gamma frequency band in the intact hippocampus in vivo.
\end{abstract}

Key words: hippocampus; in vivo; seizure; GABA; inhibition; synchronization

\section{Introduction}

Epileptic seizures result from the paroxysmal, hypersynchronous discharges in large neuronal populations. The diversity of the epileptic patterns implies a complexity of the mechanisms underlying pathological synchronization. In the hippocampus (limbic structure with a particularly high propensity to epileptic activity), several mechanisms of pathological synchronization have been identified. These include mutual excitation of the principal neurons via excitatory recurrent collateral (Miles and Wong, 1983) and depolarizing GABAergic (Cohen et al., 2002) synapses and via nonsynaptic interactions, including gap junctions, ephaptic and field effects, and ionic changes (Jefferys, 1995). Yet another mechanism of neuronal synchronization involves synchronous inhibition that operates not only during physiological patterns of activity (Freund and Buzsaki, 1996) but also in several in vitro models of rhythmic activities, including oscillations at theta (Cobb et al., 1995; Beierlein et al., 2000) and gamma frequencies induced in hippocampal slices by activation of muscarinic, metabotropic, and kainate receptors (Whittington et al., 1995; Traub et al., 1999, 2000; Hormuzdi et al., 2001). However, the role for synchronous inhibition in the pathological synchronization of epileptic activity has not been clearly demonstrated.

Kainate is a powerful epileptogenic agent that induces electrographic and clinical changes characteristic of complex partial seizures of hippocampal origin and leads, after a latent period, to the development of morphological and functional alterations in the hippocampus with spontaneous seizures that are characteristic of the temporal lobe epilepsy (Ben-Ari, 1985; Lothman and Bertram, 1993; Ben-Ari and Cossart, 2000; Dudek et al., 2002). Acute

Received Dec. 6, 2002; revised March 26, 2003; accepted March 27, 2003.

This work was supported by National Institute of Neurological Disorders and Stroke Grants NS27984 and NS41595, Institut National de la Santé et de la Recherche Médicale, and the Human Frontier Science Program. We thank Drs. G. Buzsaki, X. Leinekugel, K. Staley, and V. Dzhala for the critical reading of this manuscript.

Correspondence should be addressed to R. Khazipov, Department of Neurology, Dartmouth Medical School, One Medical Center Drive, Lebanon, NH 03756. E-mail: roustem.khazipov@dartmouth.edu.

Copyright $\odot 2003$ Society for Neuroscience $\quad$ 0270-6474/03/235337-05\$15.00/0 systemic and local administration of kainate in vivo induces complex epileptiform EEG patterns, including hippocampal highfrequency activity in the gamma $(20-80 \mathrm{~Hz})$ frequency band that evolves to complex spikes and ictal-like discharges that generalize (Ben-Ari, 1985; Bragin et al., 1999; Medvedev and Willoughby, 1999). Studies in vitro reveal multiple sites of action of kainate, including activation of cationic depolarizing currents in the principal CA3 pyramidal cells and interneurons via GluR6containing and GluR5-containing glutamate receptors, respectively (Ben-Ari and Cossart, 2000). The mechanisms of network synchronization during kainate-induced seizure activity in hippocampal slices (Lothman et al., 1981; Fisher and Alger, 1984; Ben-Ari and Gho, 1988) and intact hippocampus in vitro (Khalilov et al., 1999) involve mutual excitation mechanisms, including recurrent collateral synapses interconnecting CA3 pyramidal cells. Studies in hippocampal slices also indicate that synchronization of kainate-induced rhythmic activities in the gamma frequency band involves both glutamatergic transmission and synchronous inhibition provided by local interneurons (Traub et al., 2000; Hormuzdi et al., 2001). However, little is known about the mechanisms underlying synchronization of kainate-induced epileptiform activity in vivo.

This question was studied here using a novel preparation of superfused hippocampus in vivo that permits stable extracellular and patch-clamp recordings and pharmacological manipulations. Evidence is provided that pathological synchronization during kainate-induced rhythmic epileptiform activity in the gamma frequency band in vivo results primarily from synchronous inhibition provided by hippocampal interneurons.

\section{Materials and Methods}

This study followed National Institutes of Health guidelines on animal care, with approval from the animal care and use committees of both Harvard Medical School and Dartmouth Medical School. Sprague Dawley rats of both sexes from 2-3 weeks of age were used. Rats were anesthetized with $1.5 \mathrm{gm} / \mathrm{kg}$ urethane injected intraperitoneally. Skin and periosteum were removed from the skull, which was then covered with a 
A

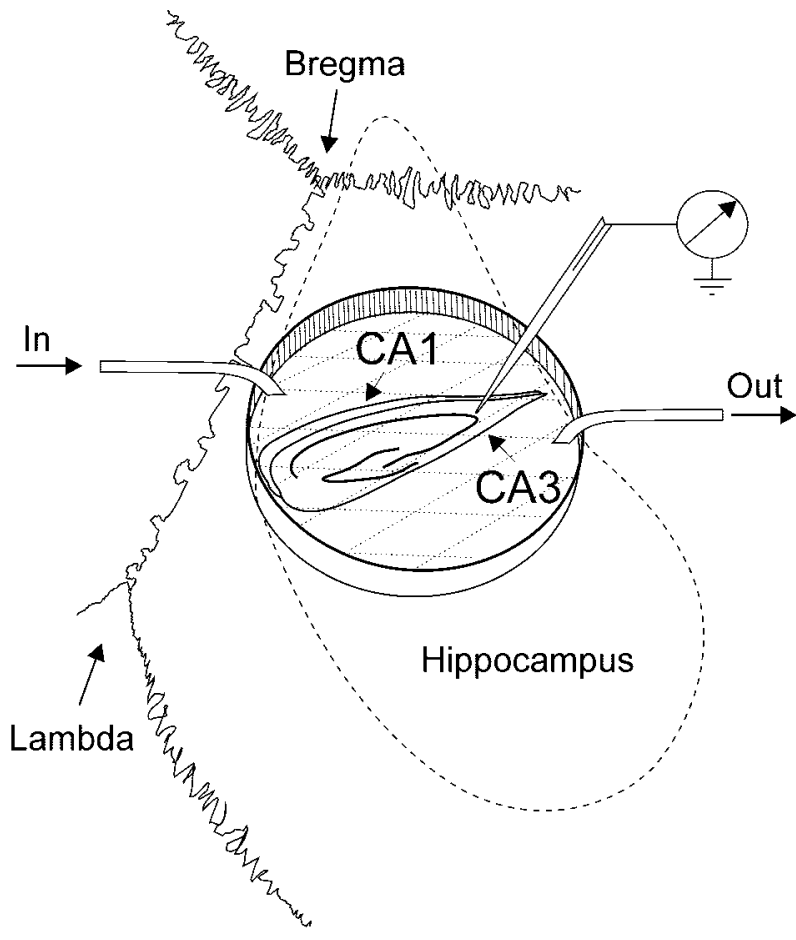

B

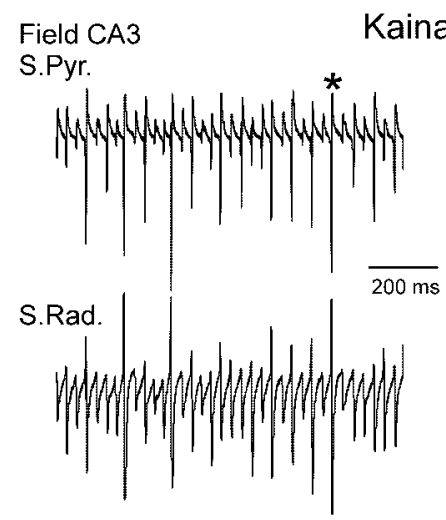

C

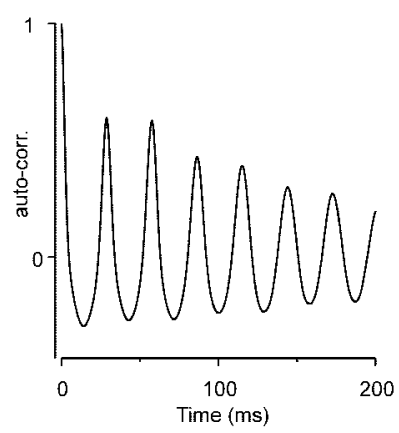

Kainate $(1 \mu \mathrm{M})$

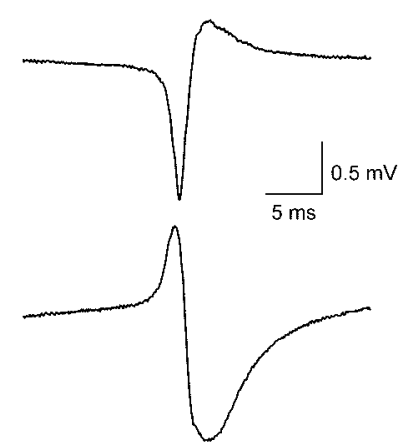

D

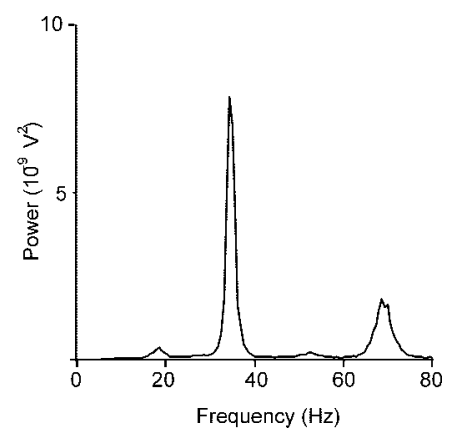

Figure 1. Kainate-induced epileptiform activity in the superfused hippocampus in vivo. A, Scheme of the experimental setup. The perfusion chamber is a cylinder with fine mesh at its bottom (dashed lines). It is placed into the cavity formed in the neocortex above the hippocampus so that mesh gently presses on the hippocampus to prevent pulsations. This construction allows application of drugs directly onto the hippocampal surface. The dorsal (CA1) and lateral (CA3a) subregions of hippocampus are indicated by arrows on the schematic transverse section of the hippocampus. $B$, Extracellular field potential recordings in the pyramidal cell layer (S. Pyr., top trace) and stratum radiatum (S. Rad., bottom trace) of the CA3a subfield of hippocampus in the presence of $1 \mu \mathrm{m}$ kainate in the perfusing solution. On the right, the population spike marked by an asterisk is shown on an expanded time scale. Autocorrelation function $(C)$ and power spectrum $(D)$ obtained using a fast Fourier transform algorithm of the kainate-induced epileptiform activity recorded in the stratum radiatum. Note the high periodicity of the population spikes occurring at $33 \mathrm{~Hz}$.

thin layer of dental acrylic, except for an area of $\sim 7 \mathrm{~mm}$ in diameter above the septal part of the hippocampus. The rat was positioned in the stereotaxic apparatus, and the skull was attached to the nose (nasal bones) and ear bars (occipital bone) with dental acrylic. The head was rotated $\sim 30^{\circ}$ "nose up" and $\sim 30^{\circ}$ counterclockwise for recordings from the right hippocampus (clockwise for recordings from the left hippocampus). These rotations were needed to put the dorsolateral portion of the CA3a region in the horizontal plane (Fig. 1). A burr hole of $6-7 \mathrm{~mm}$ in diameter was drilled in the skull above the hippocampus. Dura was cut and removed. The neocortex above the septal part of the hippocampus was removed by vacuum suction (Ben-Ari et al., 1980), and the lateral ventricle was opened exposing the CA3a and CAl regions of the hippocampus. Bleeding was stopped with Gelfoam. The hippocampus surface was covered with $0.09 \% \mathrm{NaCl}$ during the procedure to prevent it from drying.

The perfusion chamber was prepared using a 2-mm-long cylinder cut from the top of a $1 \mathrm{ml}$ plastic syringe and glued to stretched Lycra mesh with cyanacrylamide glue. The chamber was positioned in the cavity formed in the brain so that the mesh gently pressed onto the hippocampus. The chamber was then fixed to the skull by dental acrylic. Although we did not measure the amplitude of pulsations, stability and longevity of extracellular and patch-clamp recordings (up to $1.5 \mathrm{hr}$ ) indicated that the pulsations were efficiently suppressed.

During recordings, rats were heated via a thermal pad $\left(37^{\circ} \mathrm{C}\right)$. The chamber was perfused with oxygenated $\left(95 \% \mathrm{O}_{2}\right.$ and $\left.5 \% \mathrm{CO}_{2}\right)$ artificial CSF (ACSF) of the following composition (in $\mathrm{mM}$ ): $126 \mathrm{NaCl}, 3.5 \mathrm{KCl}$, 2.0 $\mathrm{CaCl}_{2}, 1.3 \mathrm{MgCl}_{2}, 25 \mathrm{NaHCO}_{3}, 1.2 \mathrm{NaH}_{2} \mathrm{PO}_{4}$, and 11 glucose, $\mathrm{pH} 7.4$ (at a rate of $2-3 \mathrm{ml} / \mathrm{min}$ ). Temperature in the chamber was kept at $35-37^{\circ} \mathrm{C}$ using an automatic temperature controller (TC-344B; Warner Instruments, Hamden, CT).
Extracellular field potential recordings were performed using metal electrodes of $50 \mu \mathrm{m}$ in diameter (California Fine Wire, Grover Beach, CA). Typically, one electrode was positioned in the CA3a pyramidal cell layer. This was determined by a sharp increase of units firing at 200-300 $\mu \mathrm{m}$ depth from the hippocampal surface. A second electrode was positioned $300 \mu \mathrm{m}$ below the first electrode in the stratum radiatum. Recordings started at least 15 min after insertion of the electrodes, when the frequency of units stabilized.

Patch-clamp recordings were performed in the pyramidal cell layer in the vicinity of the extracellular electrode (distance $<100 \mu \mathrm{m}$ ) using a Multiclamp 700A (Axon Instruments, Union City, CA) amplifier using a patching technique similar to that described in vivo (Leinekugel et al., 2002; Margrie et al., 2002). For cell-attached and loose cell-attached recordings, pipettes (GC150F-15; Clark Electromedical Instruments, Pangbourne, UK) were filled with ACSF. For whole-cell recordings, the pipettes were filled with a solution of the following composition (in $\mathrm{mM}$ ): 135 Cs-gluconate, $2 \mathrm{MgCl}_{2}, 0.1 \mathrm{CaCl}_{2}, 1$ EGTA, and 10 HEPES, pH 7.25. Membrane potential values were corrected for liquid junction potential of $+12 \mathrm{mV}$, seal resistance was in the range of 2-20 G $\Omega$, and series resistance was 5-25 $\mathrm{M} \Omega$.

Data were digitized at $10 \mathrm{~Hz}$ using Digidata 1322A interface (Axon Instruments) and analyzed offline using an Axon package (Axon Instruments), MiniAnalysis (Synaptosoft, Decatur, GA), and Origin (Microcal Software, Northampton, MA). Power spectra of extracellular field potential recordings were obtained from $3-5$ min records using a fast Fourier transform algorithm (Clampfit 8.2; Axon Instruments). Rectangular windowing function was used. Spectral segments of 8192 samples (spectral resolution of $1.22 \mathrm{~Hz}$ ) were averaged with $50 \%$ window overlap. Group measures are expressed as means \pm SE. The statistical significance 

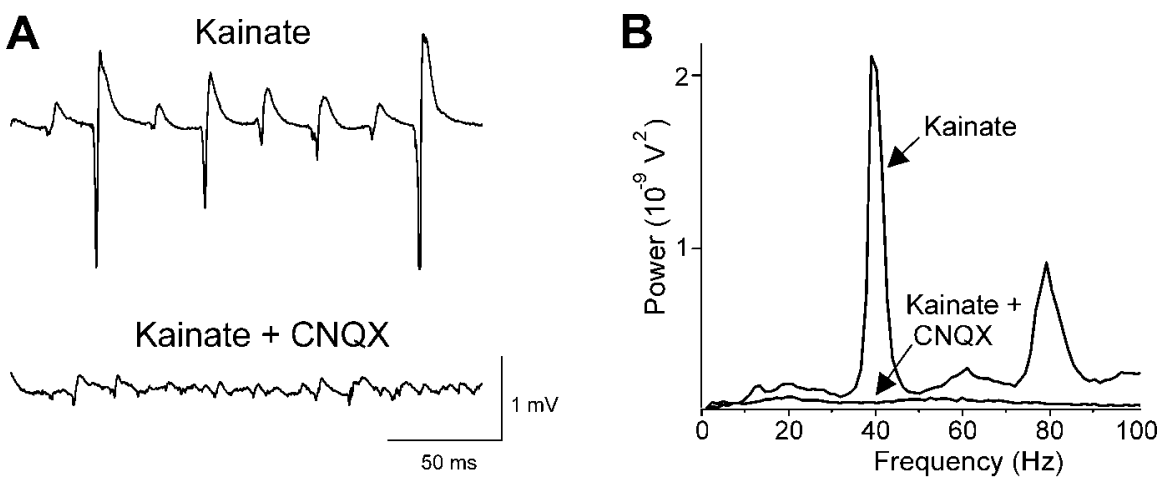

Figure 2. AMPA/kainate receptor antagonist CNQX suppresses the kainate-induced epileptiform activity. $A$, Field potential recordings in the pyramidal cell layer of CA3a in the superfused rat hippocampus in the presence of kainate (1 $\mu \mathrm{M})$ in the superfusing solution and $15 \mathrm{~min}$ after addition of CNQX (50 $\mu \mathrm{M})$. Note that the regularly occurring population spikes are suppressed by CNQX. B, Power spectrum of the field potential in the presence of kainate and kainate plus CNQX. Note that the kainate-induced periodic epileptiform activity in the gamma frequency range is totally suppressed by CNQX.

of differences was assessed with the Student's $t$ test. The level of significance was set at $p<0.05$.

Drugs used were as follows: kainate from BioVectra (Prince Edward Island, Canada), bicuculline, CNQX, and (RS)-2- $\alpha$-amino-3-(3hydroxy-5-tert-butylisoxazol-4-yl) propanoic acid (ATPA) from Tocris Cookson (Bristol, UK), pentobarbital from Abbott Laboratories (North Chicago, IL), and other compounds from Sigma (St. Louis, MO).

\section{Results}

We used an original technique for perfusion and recordings from the rat hippocampus in vivo. The experimental setup is schematically shown in Figure $1 A$. In brief, under urethane anesthesia, a cavity is formed in the brain just above the hippocampus. Into this cavity is placed a cylinder with fine mesh at its bottom, which gently presses on the hippocampus. Mesh prevents pulsations and allows application of drugs directly onto the hippocampal surface. In addition to the ease of pharmacological manipulations, this preparation is also convenient for placement of electrodes and patch-clamp recordings.

Addition of kainate $(1 \mu \mathrm{M})$ to the perfusion solution invariably produced epileptic population spikes in the CA3a subfield of the hippocampus (Fig. 1B). Population spikes reversed near the pyramidal cell layer (Fig. $1 B$, right) and occurred at a frequency of $34 \pm 1 \mathrm{~Hz}(n=32)$. Kainate-induced epileptiform activity was highly periodic, as evidenced by a fast Fourier transform algorithm and autocorrelation analysis (Fig. 1C,D). Kainate-induced epileptiform activity was completely and reversibly suppressed by the AMPA/kainate glutamate receptor antagonist CNQX (50 $\mu \mathrm{M}$; $n=5$ ) (Fig. 2). The selective GluR5 agonist ATPA (1-5 $\mu \mathrm{M})$ failed to reproduce the effect of kainate or induce any other epileptiform activity $(n=4)$, suggesting that depolarization of CA3 pyramidal cells via GluR6 receptors is required for generation of the kainate-induced epileptiform activity.

Behavior of individual pyramidal cells during the epileptiform discharges was studied using cell-attached and loose cell-attached recordings (Fig. 3). Firing of putative CA3 pyramidal cells was tightly locked to the population spikes. Typically, pyramidal cells fired no more than one action potential during the population spike, with an average probability of firing of $0.34 \pm 0.08$ action potentials per population spike $(n=14)$. Cross-correlations of the times of action potentials in the individual neuron versus the times of population spikes revealed sharp peaks coinciding with the population spikes and virtually complete silence in the phase between the population spikes (Fig. 3B).
Whole-cell recordings were also used to determine the synaptic conductances activated during the epileptiform activity (Fig. 4). Voltage-clamp recordings with low-chloride solution at the reversal potential of the glutamatergic currents $(0$ $\mathrm{mV} ; n=9$ ) revealed robust and rhythmic collective $\mathrm{GABA}_{\mathrm{A}}$-mediated IPSCs generated during each cycle of the epileptiform activity. Collective synaptic events reversed their polarity at $-69 \pm 2 \mathrm{mV}(n=$ 5 ), which corresponds to the reversal potential of chloride-mediated $\mathrm{GABA}_{\mathrm{A}}$ conductance. Recordings at the reversal potential of the $\mathrm{GABA}_{\mathrm{A}}$-mediated currents revealed little or no AMPA receptormediated EPSCs during the population activity (Fig. 4, trace at $-70 \mathrm{mV})(n=5)$.

Collective $\mathrm{GABA}_{\mathrm{A}}$-mediated IPSCs were tightly phase locked to the population spikes and were associated with the phase of inhibition of multiple unit activity (MUA) between the population spikes (Fig. $5 A, B)$. Cross-correlations of the times of action potentials from multiple units recorded with extracellular electrodes versus the $\mathrm{GABA}_{\mathrm{A}}$-mediated collective IPSCs were made. During each cycle, the rising phase of IPSCs coincided with cessation of MUA associated with the population spikes. Firing associated with the next population spike progressively increased during decay of the IPSC, reaching a maximum when the IPSCs decay to baseline.

Blockade of $\mathrm{GABA}_{\mathrm{A}}$ receptors by perfusion of the selective antagonist bicuculline $(20 \mu \mathrm{M})$ induced a complete and reversible suppression of the rhythmic $\mathrm{GABA}_{\mathrm{A}}$-mediated collective IPSCs and population spikes $(n=5)$ (Fig. $5 C$ ). Instead of the activity in the gamma frequency band, much slower-occurring ictal-like and interictal-like events were observed during the conditions of combined perfusion with kainate and bicuculline. As evidenced by fast Fourier transform analysis (Fig. 5D), bicuculline induced virtually complete suppression of the rhythmic population activity in the gamma frequency band.

Barbiturates are known to increase GABAergic inhibition by prolonging the openings of $\mathrm{GABA}_{\mathrm{A}}$ channels. Application of pentobarbital $(200 \mu \mathrm{M})$ in the presence of kainate induced a shift of the peak of oscillations toward slower frequency (from $34 \pm 2$ to $29 \pm 1 \mathrm{~Hz} ; n=4 ; p<0.05)$.

\section{Discussion}

We used a novel methodological approach of superfused hippocampus in vivo to provide a stable platform for electrophysiological extracellular and patch-clamp recordings and pharmacological manipulation. Using this approach, we provide evidence for the pivotal role of GABAergic inhibition in synchronization of kainate-induced epileptiform activity in vivo.

Advantages of the present technique compared with conventional in vivo recordings can be summarized as follows: (1) the hippocampus is exposed, and the recording electrodes can be placed under visual control as easy as in the intact hippocampus in vitro (Khalilov et al., 1997); (2) the success of patch-clamp recordings is significantly higher compared with the approach to the hippocampus through neocortex (Leinekugel et al., 2002), and access resistance is significantly lower compared with recordings with sharp electrodes; and (3) rapid pharmacological manipulations including application and washout of drugs is possible. This is a distinct advantage over other in vivo models that require 
A

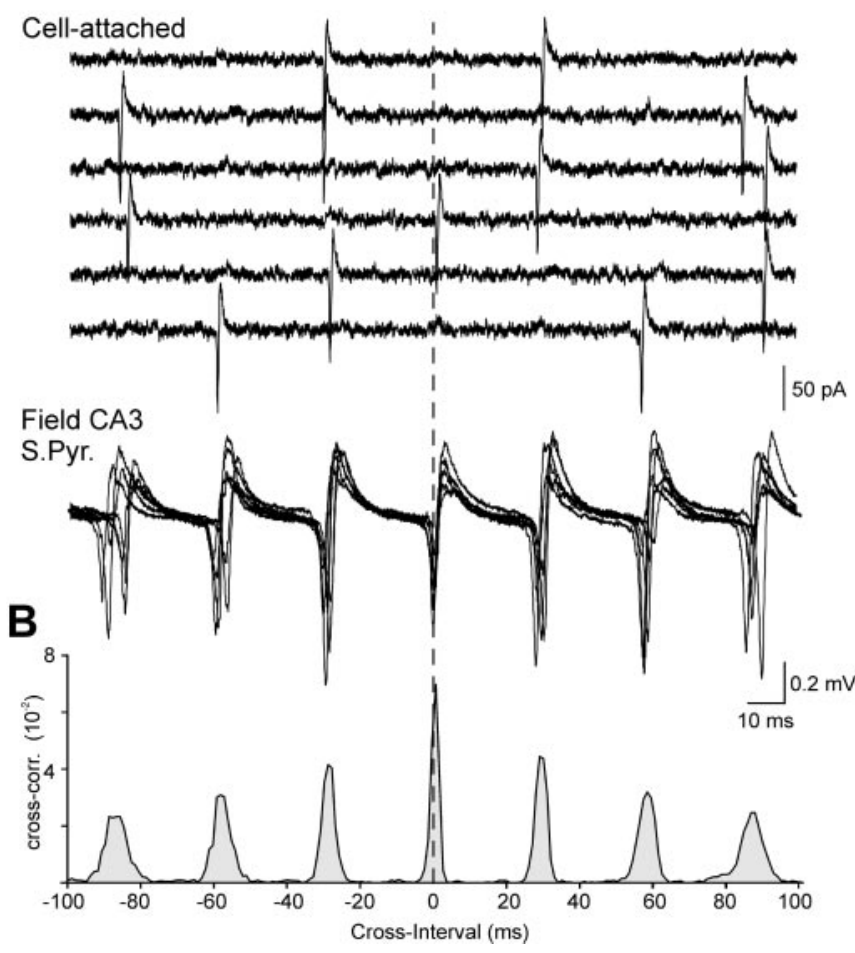

Figure 3. Contribution of individual pyramidal cells. A, Cell-attached recordings from CA3 pyramidal cell layer and concomitant extracellular field potential recordings. Traces represent random episodes aligned with the population spike in the middle (dashed line). Traces of extracellular recordings are superimposed. $B$, Cross-correlogram of the times of action potentials in cell-attached recordings versus the times of population spikes in extracellular field recordings ( 6000 cycles; a bin is $1 \mathrm{msec}$ ). S. Pyr., Pyramidal cell layer.

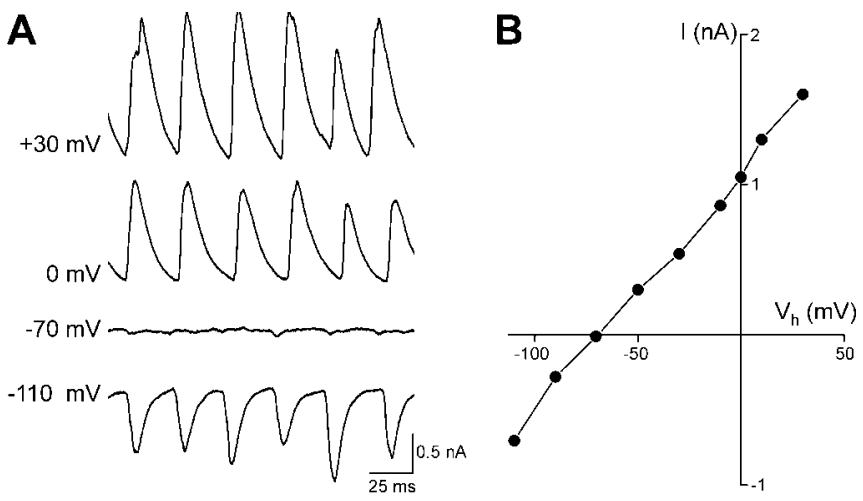

Figure 4. Synaptic correlates of the kainate-induced epileptiform activity. $A$, Simultaneous extracellular field and whole-cell recordings from the CA3a pyramidal cell layer. Note the reversal of synaptic currents at approximately $-70 \mathrm{mV}$, corresponding to the reversal potential of $G_{A B A_{A}}$ IPSCS. $B$, Current-voltage relationships of the synaptic currents activated during oscillations. $R_{\mathrm{s}}=6 \mathrm{M} \Omega$.

systemic or local injections. Thus, the preparation of the superfused hippocampus combines the in vitro approaches with the in vivo situation. It can be particularly useful for studies of physiological and paroxysmal activities that appear to be much more complex in the intact brain than in isolated slices (Steriade, 2001).

Using this technique, we provide here evidence for the principal role of synchronous GABAergic inhibition in patterning the kainate-induced rhythmic epileptiform activity in the gamma frequency range in vivo. Our conclusion is based on a number of findings: (1) the phase lock of the rhythmic $\mathrm{GABA}_{\mathrm{A}}$-mediated
A
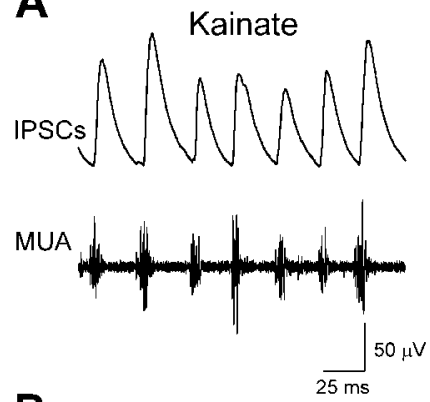

B
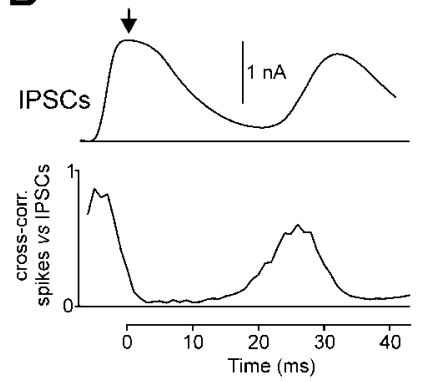

C Kainate + Bicuculline
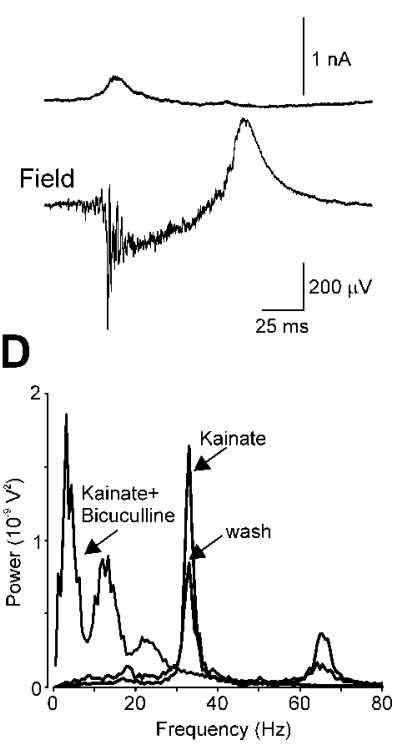

Figure 5. GABA -mediated IPSCS participate in synchronization of the kainate-induced epileptiform activity. $A, G A B A_{A} I P S C S$ were recorded from a putative CA3a pyramidal cell in wholecell mode at a holding potential $0 \mathrm{mV}$. Bottom trace represents concomitant recordings of MUA in the CA3 pyramidal cell layer (high-pass, $500 \mathrm{~Hz}$ ). B, Average collective IPSC is plotted above the cross-correlation of the times of spikes recorded with an extracellular electrode against the times of the peak of collective IPSCS (>1000 cycles). Note that phasic inhibition of neuronal firing coincides with the time course of the $G_{A B A_{A}}$-mediated currents. C, GABA $A_{A}$ receptor antagonist bicuculline $(20 \mu \mathrm{M})$ suppresses kainate-induced oscillations and induces interictal-like and ictal-like activities. Recordings from the same neuron shown in A.D, Power spectra of extracellular field potential recordings in the presence of kainate, after addition of bicuculline and after $15 \mathrm{~min}$ of wash of bicuculline obtained using a fast Fourier transform algorithm.

IPSCs with population spikes; (2) the match between the time course of $\mathrm{GABA}_{\mathrm{A}}$-mediated signals and inhibition of the multiple unit activity between the population discharges; (3) suppression of the rhythmic activity in the gamma frequency range by the $\mathrm{GABA}_{\mathrm{A}}$ receptor antagonist bicuculline; and (4) reduction of its frequency by barbiturates. Our results suggest the following model for kainate-induced epileptiform activity. Kainate produces tonic depolarization of the hippocampal neurons and increases their firing rate. With GABAergic inhibition intact, neuronal activity is locked by synchronous inhibition provided by a collective discharge of interneurons. At the end of the collective $\mathrm{GABA}_{\mathrm{A}}$-mediated inhibitory events, probability of firing of pyramidal cells increases, and approximately one-third of them fire rebound action potentials, giving rise to the next population spike. Synchronization of interneuronal discharge probably relies on a similar mechanism, but direct recordings from interneurons are needed to clarify this issue.

The pathological synchronization of kainate-induced activity in the gamma frequency range appears to involve synchronous inhibition that has been described previously during physiological gamma oscillations in vivo (Bragin et al., 1995; Traub et al., 1996; Penttonen et al., 1998), as well as in several models of activity in the gamma frequency band, including oscillations induced by activation of muscarinic (Fisahn et al., 1998), metabotropic (Whittington et al., 1995), and kainate (Traub et al., 2000; Hormuzdi et al., 2001) receptors in hippocampal slices. Our finding further confirms a propensity of the cortical networks to oscillate at a gamma frequency. From the mechanistic point of view, kainate-induced epileptiform activity described in this 
study is reminiscent of "interneuron-based" oscillations that can be induced in slices by activation of metabotropic glutamate receptors or by tetanic electrical stimulation (Whittington et al., $1995)$. First, the probability of pyramidal cells firing was very high $(\sim 34 \%)$, whereas it does not exceed 5\% during physiological gamma activity and oscillations at gamma frequency induced in the hippocampal slices by carbachol (Fisahn et al., 1998) or submicromolar concentrations of kainate (Traub et al., 2000; Hormuzdi et al., 2001). Second, whereas the contribution of AMPA receptor-mediated EPSCs is essential for carbachol and kainateinduced oscillations in slices (Fisahn et al., 1998; Hormuzdi et al., 2001), in the case of kainate-induced epileptiform activity in vivo and metabotropic/tetanic-induced gamma activity in vitro (Whittington et al., 1995), the contribution of AMPA EPSCs appears to be minor. The latter observation is somewhat paradoxical because the probability of pyramidal cells firing during each cycle is very high, and one would expect large collective EPSCs as a result of summation of EPSCs in the recurrent collateral synapses. Although the reason for limited participation of EPSCs to the kainate-induced epileptiform activity is unclear, it can be suggested that it is attributable to kainate-induced (Chittajallu et al., 1996; Kamiya and Ozawa, 2000) and/or activity-dependent (Staley et al., 1998) suppression of glutamate release in the recurrent collateral synapses. In addition, robust $\mathrm{GABA}_{\mathrm{A}}$-mediated collective IPSCs may efficiently shunt the glutamatergic EPSCs.

In conclusion, GABAergic interneurons play a pivotal role in synchronization of rhythmic epileptiform activity in the gamma frequency band induced by kainate in the rat hippocampus in vivo. Although the clinical relevance of this mechanism remains to be determined, it is suggested that synchronization via inhibition may operate in patients with epilepsy during the preictal phase that is characterized by an increase in the power in the gamma frequency band (Alarcon et al., 1995). Additional study is required to determine the consequences of the rhythmic epileptiform activities occurring at gamma frequencies.

\section{References}

Alarcon G, Binnie CD, Elwes RD, Polkey CE (1995) Power spectrum and intracranial EEG patterns at seizure onset in partial epilepsy. Electroencephalogr Clin Neurophysiol 94:326-337.

Beierlein M, Gibson JR, Connors BW (2000) A network of electrically coupled interneurons drives synchronized inhibition in neocortex. Nat Neurosci 3:904-910.

Ben-Ari Y (1985) Limbic seizure and brain damage produced by kainic acid: mechanisms and relevance to human temporal lobe epilepsy. Neuroscience 14:375-403.

Ben-Ari Y, Cossart R (2000) Kainate, a double agent that generates seizures: two decades of progress. Trends Neurosci 23:580-587.

Ben-Ari Y, Gho M (1988) Long-lasting modification of the synaptic properties of rat CA3 hippocampal neurons induced by kainic acid. J Physiol (Lond) 404:365-384.

Ben-Ari Y, Krnjevic K, Reinhardt W (1980) Lability of synaptic inhibition of hippocampal pyramidal cells. J Physiol (Lond) 298:36P-37P.

Bragin A, Jando G, Nadasdy Z, Hetke J, Wise K, Buzsaki G (1995) Gamma $(40-100 \mathrm{~Hz})$ oscillation in the hippocampus of the behaving rat. J Neurosci 15:47-60.

Bragin A, Engel Jr J, Wilson CL, Vizentin E, Mathern GW (1999) Electrophysiologic analysis of a chronic seizure model after unilateral hippocampal KA injection. Epilepsia 40:1210-1221.

Chittajallu R, Vignes M, Dev KK, Barnes JM, Collingridge GL, Henley JM (1996) Regulation of glutamate release by presynaptic kainate receptors in the hippocampus. Nature 379:78-81.
Cobb SR, Buhl EH, Halasy K, Paulsen O, Somogyi P (1995) Synchronization of neuronal activity in hippocampus by individual GABAergic interneurons. Nature 378:75-78.

Cohen I, Navarro V, Clemenceau S, Baulac M, Miles R (2002) On the origin of interictal activity in human temporal lobe epilepsy in vitro. Science 298:1418-1421.

Dudek FE, Hellier JL, Williams PA, Ferraro DJ, Staley KJ (2002) The course of cellular alterations associated with the development of spontaneous seizures after status epilepticus. Prog Brain Res 135:53-65.

Fisahn A, Pike FG, Buhl EH, Paulsen O (1998) Cholinergic induction of network oscillations at $40 \mathrm{~Hz}$ in the hippocampus in vitro. Nature 394:186-189.

Fisher RS, Alger BE (1984) Electrophysiological mechanisms of kainic acidinduced epileptiform activity in the rat hippocampal slice. J Neurosci 4:1312-1323.

Freund TF, Buzsaki G (1996) Interneurons of the hippocampus. Hippocampus 6:347-470.

Hormuzdi SG, Pais I, LeBeau FE, Towers SK, Rozov A, Buhl EH, Whittington MA, Monyer H (2001) Impaired electrical signaling disrupts gamma frequency oscillations in connexin 36-deficient mice. Neuron 31:487-495.

Jefferys JG (1995) Nonsynaptic modulation of neuronal activity in the brain: electric currents and extracellular ions. Physiol Rev 75:689-723.

Kamiya H, Ozawa S (2000) Kainate receptor-mediated presynaptic inhibition at the mouse hippocampal mossy fibre synapse. J Physiol (Lond) 523:653-665.

Khalilov I, Esclapez M, Medina I, Aggoun D, Lamsa K, Leinekugel X, Khazipov R, Ben-Ari Y (1997) A novel in vitro preparation: the intact hippocampal formation. Neuron 19:743-749.

Khalilov I, Dzhala V, Medina I, Leinekugel X, Melyan Z, Lamsa K, Khazipov R, Ben-Ari Y (1999) Maturation of kainate-induced epileptiform activities in interconnected intact neonatal limbic structures in vitro. Eur J Neurosci 11:3468-3480.

Leinekugel X, Khazipov R, Cannon R, Hirase H, Ben-Ari Y, Buzsaki G (2002) Correlated bursts of activity in the neonatal hippocampus in vivo. Science 296:2049-2052.

Lothman EW, Bertram III EH (1993) Epileptogenic effects of status epilepticus. Epilepsia 34 [Suppl 1]:S59-S70.

Lothman EW, Collins RC, Ferrendelli JA (1981) Kainic acid-induced limbic seizures: electrophysiologic studies. Neurology 31:806-812.

Margrie TW, Brecht M, Sakmann B (2002) In vivo, low-resistance, wholecell recordings from neurons in the anaesthetized and awake mammalian brain. Pflügers Arch 444:491-498.

Medvedev A, Willoughby JO (1999) Autoregressive modeling of the EEG in systemic kainic acid-induced epileptogenesis. Int J Neurosci 97:149-167.

Miles R, Wong RKS (1983) Single neurones can initiate synchronized population discharge in the hippocampus. Nature 306:371-373.

Penttonen M, Kamondi A, Acsady L, Buzsaki G (1998) Gamma frequency oscillation in the hippocampus of the rat: intracellular analysis in vivo. Eur J Neurosci 10:718-728.

Staley KJ, Longacher M, Bains JS, Yee A (1998) Presynaptic modulation of CA3 network activity. Nat Neurosci 1:201-209.

Steriade M (2001) Impact of network activities on neuronal properties in corticothalamic systems. J Neurophysiol 86:1-39.

Traub RD, Whittington MA, Colling SB, Buzsaki G, Jefferys JG (1996) Analysis of gamma rhythms in the rat hippocampus in vitro and in vivo. J Physiol (Lond) 493:471-484.

Traub RD, Jefferys JG, Whittington MA (1999) Functionally relevant and functionally disruptive (epileptic) synchronized oscillations in brain slices. Adv Neurol 79:709-724.

Traub RD, Bibbig A, Fisahn A, LeBeau FE, Whittington MA, Buhl EH (2000) A model of gamma-frequency network oscillations induced in the rat CA3 region by carbachol in vitro. Eur J Neurosci 12:4093-4106.

Whittington MA, Traub RD, Jefferys JG (1995) Synchronized oscillations in interneuron networks driven by metabotropic glutamate receptor activation. Nature 373:612-615. 